\title{
Kön och socialt arbete - en introduktion
}

\section{ULLA-CARIN HEDIN \& SVEN-AXEL MÅNSSON}

Det råder oenighet ompå vilket sätt den sociala könsordningen har förändrats under de gångna decennierna. A ena sidan finns det inget tvivel om att kvinnorna har flyttat fram sina positioner på den offentliga arenan. Kvinnor deltar mer i politik, utbildning och förvärvsarbete än tidigare. Åandra sidan hävdar många, inte minst kvinnoforskare, att den jämställdhet vi fätt är en jämställdhet på männens villkor. Mansdominansen har egentligen inte försvagats, bara förändrats till form och innehåll.

Resultatet av Kvinnomaktutredningens 13 volymer om fördelningen av ekonomisk makt och ekonomiska resurser mellan kvinnor och män är att myten om det jämställda Sverige rämnar (SOU 1998:6). Trots att kvinnor och män arbetar lika mycket, om hänsyn tas till såväl betalt som obetalt arbete, är det stora skillnader i kvinnors och mäns tillgång till olika resurser. Det kanske mest slående resultatet av de olika studier

Ulla-Carin Hedin är fil dr i socialt arbete och verksam som universitetslektor i socialt arbete vid Göteborgs universitet. Hennes forskning ingår i forskningsprogrammet Kön, sexualitet och socialt arbete vid institutionen.

Sven-Axel Månsson är professor i socialt arbete och ansvarig för forskningsprogrammet Kön, sexualitet och socialt arbete vid Institutionen för socialt arbete, Göteborgs universitet som genomfördes inom utredningens ram är det som har kommit att kallas den "negativa kvinnoeffekten«. Denna kan mätas i kronor och ören. En grov beräkning av skillnaden mellan timpenningen för kvinnor och män inom kvinno-respektive mansdominerade yrken visar att kostnaden att vara kvinna i ett kvinnoyrke jämfört med att vara man i ett mansyrke är 16,68 kr i timmen (år 1997). Även när kvinnor väljer att utbilda sig otraditionellt - eller utbilda sig överhuvudtaget - lönar sig utbildning sämre för kvinnor. Både i fråga om karriär och löneutveckling har en väl utbildad kvinna svårt att konkurrera ut en man med lägre utbildning. „Könsbyte lönar sig faktiskt bättre än utbildning för kvinnor", konstaterar utredningen lakoniskt. Finns det då ingenting som blivit bättre under senare år? Jo, svarar 
utredningen, några saker: kvinnors inkomster har närmat sig männens, kvinnor är idag mindre ekonomiskt beroende av sina män, arbetslösheten har inte drabbat kvinnor hårdare än män och pappor tar idag ett större vardagligt ansvar för sina barn. Allt detta är bra, säger utredningen, men det kan bli mycket bättre.

Trots dessa förändringar är det fortfarande så att män i högre utsträckning intar olika maktpositioner i samhället. Detta innebär emellertid inte detsamma som att alla män har samma tillgång till makten. Den nya mansforskningens analyser av manliga hierarkier har visat att det är först i samspelet med andra sociala strukturer - t.ex. klass och etnicitet - som dynamiken i könsrelationerna blir tydlig (Connell, 1995; Hearn, 1996). I ett samhälle som vårt, som präglas av stora och grundläggande strukturella förändringar, påverkas förstås den manliga hierarkin i olika avseenden. För de män som tidigare förankrade sin identitet $i$ klassiskt manliga yrken leder omstruktureringen på arbetsmarknaden och $\mathrm{i}$ arbetslivet till svåra omställningsproblem. Samma sak gäller för de utländska män vars flyttning till Sverige blir ett led i en nedåtgående social och klassmässig spiral. En sådan omstrukturering leder ofta till en upplevelse av marginalisering och utanförskap. Men enskilda mäns reaktioner på detta förändringstryck kan se olika ut. En del svarar med att förändra sin manlighet, andra med att krampaktigt försvara sina privilegier som män (jfr Thomas Johanssons artikel i detta nummer). Och även om marginaliseringsprocessen för många män leder till en förstärkning av manliga dominansmönster och en polarisering av relationerna mellan kö- nen, finns också exempel på andra strategier. En del män ser möjligheter till en konstruktiv anpassning och en förändrad syn på sig själva som män och på sitt förhållande till kvinnor och barn (jfr artikeln om mäns föräldraskap av Plantin, Månsson \& Kearney).

Den nya mansforskningen erbjuder en förståelse av kön som en social praktik, genom vilken könsliga relationer förändras över tid och i samspel både med samhälleliga förhållanden på olika nivåer och med vardagliga relationer mellan män och kvinnor. Det betyder också att de föreställningar om kön som genomsyrar den hierarkiska logiken - mannen som norm - är en social produkt. Kön är med andra ord ingen enkel återspegling av de naturgivna eller biologiska förutsättningar som finns i vår kroppsliga konstitution eller våra kroppsliga funktioner.

Ett sådant synsätt har bestämda implikationer både för forskning och praktik. I stället för "eviga upprepningar» av vad som är "kvinnligt» eller "manligt" förpliktigar det till noggranna funderingar och studier om mäns och kvinnors konkreta, praktiska handlingar i vardaglivets relationer (jfr Margareta Hydéns artikel). Det är först när vi fokuserar på dessa förhållanden som vi kan förstå att kön inte är någonting i sig själv, en mental eller abstrakt kategori utan förankring i materiella, sociala eller kulturella omständigheter. Det är viktigt att vi börjar inse att manliga och kvinnliga relationer och interaktionssätt är produkter av det könsorganiserade samhället och dess fördelning av positioner. När vi talar om "män" och "kvinnor" måste vi således fråga oss: vilka män eller vilka kvinnor? och i vilken situation? Utan sådana preciseringar blir talet om kön 
meningslöst och oanvändbart både i forskning och praktik. Men inte bara meningslöst och oanvändbart, utan också kontraproduktivt, särskilt om det är förändring vi vill åstadkomma.

\section{Kön i socialt arbete}

1990-talet har medfört ett ökat intresse för könsperspektiv i socialt arbete, både i teori och praktik. Uppfattningen är att det inte längre räcker att beskriva könsspecifika mönster eller hur sociala problem är könsstrukturerade. Både forskare och praktiker vill veta hur kvinnors och mäns sociala verklighet är konstruerad, vilken dynamik och vilka processer som producerar den rådande könsordningen, vilka problem och orättvisor som den förorsakar samt hur socialpolitik och praxis kan verka för en förändring. Intresset för könsteoretisk forskning har således större ambitioner nu än tidigare (jfr Evy Gunnarssons artikel). Artiklarna i detta nummer av Socialvetenskaplig tidskrift speglar dessa ambitioner.

En bidragande orsak till detta är den könscentrerade praktik som redan vuxit fram inom flera sociala arbetsområden t.ex. inom institutionsvården, inom hälsoområdet och inom s.k. frivilligt socialt arbete (t.ex. kvinno- och mansjourer). Denna praktik är i stor utsträckning påverkad av feministisk forskning, både nordisk och amerikansk. Den är också i hög grad influerad av arbetsmodeller från våra grannländer. Här och var finns länkar till forskningen i socialt arbete men utvecklingen av nya arbetssätt leds huvudsakligen från andra ideologiska centra (t.ex. från stiftelsen Kvinnoforum och dess olika nätverk). Man kan se hur en experimenterande och kreativ praktik går före och hur kunskapsbildningen $\mathrm{i}$ ämnet socialt arbete ibland följer efter som legitimerande bekräftelse. Bland yrkesverksamma socialarbetare växer nu olika nätverk fram för att utveckla nya kunskaper kring könsfrågor och mer könsspecifika arbetsmetoder (t.ex. nätverket Kvinnokonsulterna inom kriminalvården).

Sålunda finns idag flera viktiga element för att utveckla och fördjupa könsforskningen i socialt arbete. Inom ämnet finns traditioner av könsforskning kring utsatta grupper (t.ex. Takman 1966; Jonsson 1969 och 1977). Internationell kvinno- och mansforskning kan bidra med fruktbara begrepp och teorier. Och det finns redan en könscentrerad praktik att undersöka och vidareutveckla. Framförallt finns ett omfattande intresse för könsfrågor bland såväl forskare och studenter som bland yrkesverksamma socialarbetare, vilket troligen bottnar i en ny medvetenhet om könsfrågornas stora betydelse för både yrkes- och privatlivet.

Urvalet av artiklar i detta nummer av Socialvetenskaplig tidskrift ger en bild av forskning med ett tydligt könsperspektiv som för närvarande bedrivs inom ämnet socialt arbete. Det är inget heltäckande urval, därför vill vi i den här introduktionen diskutera också några andra angelägna områden, där sådan forskning borde bedrivas. Men låt oss börja med en kort översikt över den forskning som just nu görs på området.

\section{Vilken könsforskning bedrivs i socialt arbete?}

Ett könsperspektiv i socialt arbete handlar självfallet om vilka frågor som ställs och vil- 
ka problem man väljer att utforska. Hittills har huvuddelen av forskningen i socialt arbete varit könsneutral och i vissa fall »könsblind». Många teorier i socialt arbete har ansetts vara av generell karaktär och gälla i lika mån för män och kvinnor. Forskarna har inte uppmärksammat de könsspecifika livsvillkor som föreligger eller hur mäns och kvinnors livslopp ofta utvecklas olika. Man har heller inte fokuserat de sociala problemens könsspecifika aspekter och att sociala insatser därför kan få helt olika utfall. Inom forskningen kring missbruk har man fått skilda undersökningsresultat för män och kvinnor men först på senare år förstått deras implikationer för det sociala arbetet (Leissner, 1997). Hittills har könsforskningen i socialt arbete omfattat vissa ämnen eller problemområden, där könsfrågorna mer självklart framträder. Man kan urskilja fem huvudområden i forskningen:

\section{Forskning kring kvinnors fattigdom, soci- albidragstagande och ensamstående mödrars} försörjningssituation

Central tycks frågan om den s.k. feminiseringen av fattigdomen vara (jfr Evy Gunnarssons artikel). Denna forskning är en del av den socialpolitiska välfärdsforskningen och har en makroinriktad och kvantitativ prägel. Få av studierna inom fältet undersöker kvinnornas faktiska livssituation, deras tänkesätt och handlingar. Istället finns en tendens att skapa stereotypa kategorier, som tenderar att stigmatisera grupper av kvinnor (jfr Mona Scheffer Kumpulas artikel). Kvinnors beroende av arbetsmarknadens funktionssätt och offentliga sektorns resurser är tydligt. Ändå belyser ganska få studier hur kvinnor "samspelar" med offentliga organ och hur de blir behandlade av offentliga sektorns tjänstemän (jfr Therese Halskovs artikel). Här skulle behövas mer forskning av kvalitativ karaktär, dels s.k. livsloppsforskning om hur kvinnors och mäns liv faktiskt gestaltar sig, dels hur den offentliga sektorns organ behandlar kvinnor och män i olika avseenden. Troligen behövs studier där man förenar ett könsperspektiv med ett klassperspektiv och ett etniskt perspektiv på dessa frågor.

\section{Forskning kring familiemönster, familiens} ändrade funktioner och föräldraskapets omdaning för män och kvinnor

Detta forskningsområde har vuxit snabbt under senare år och en rad studier har presenterats (Hyvönen, 1993; Bäck-Wiklund \& Bergsten, 1997; Plantin \& Månsson, 1999). Studier av sociala problem inom familjen hör naturligtvis också hit, t.ex. på områdena kvinnomisshandel, sexuella övergrepp och barnmisshandel (t.ex. Hydén, 1994 och 1995; Hedlund, 1995). I dessa studier har det varit i det närmaste ofrånkomligt att anlägga ett könsperspektiv. En allmän bild av mannen som våldsverkare och förövare och kvinnan och barnen som offer har vuxit fram. Vissa studier har dock utmanat den gängse bilden och visat familjevåldets karaktär av samspel och ömsesidig kommunikation (Lennéer-Axelson, 1989; Hydén, 1994). Forskarna i socialt arbete har haft förmånen att kunna anknyta till en välutvecklad nordisk forskning på familjelivets område, sedd ur både ett kvinno-och mansperspektiv (Haavind \& Andenäs, 1990; Holter \& Aarseth, 1993; Bak, 1997). 


\section{Forskning kring kön och sexualitet}

Denna forskningsgren har flera inriktningar, den första mot heterosexuell sexualitet $i$ allmänhet, t.ex. genom studier av svenskars sexualvanor (jfr Lalos artikel). I tvärvetenskapliga studier har forskarna undersökt sexualvanornas förändring över tid och jämfört med liknande rön från andra länder Studierna har producerat översiktlig kunskap och mycket statistiska uppgifter, men fortfarande behövs fördjupade analyser av kvalitativ art för att kunna förstå den förändrade mentalitet som ligger bakom beteendeförändringarna. Den andra inriktningen inom detta fält riktar uppmärksamheten mot olika uttryck för en "problematisk" sexualitet. Detta sker t.ex. genom studier av könsköpares bakgrund och motiv till köp av sexuella tjänster eller av prostituerade kvinnors väg in i och ut ur prostitutionen (Månsson \& Linders, 1984; Hydén, 1990; Sandell m.fl., 1996, Hedin \& Månsson, 1998). Studier av avvikande manlig sexualitet förekommer också, t.ex. av sexualbrottslingars problematik och behandling (Kvarnmark \& Tidefors Andersson, 1999). En tredje inriktning handlar om kroppens betydelse för synen på unga kvinnors sexualitet och stigmatisering (jfr Schlytters artikel). Den fjärde inriktningen gäller studier av homo- och bisexuella personers livslopp, familjebildning och sätt att hantera kriser och problemsituationer (Henriksson, 1995). Inom detta fält bedrivs också forskning om hiv och hivprevention (Henriksson, op.cit., NilssonSchönnesson, 1999; Tikkanen \& Månsson, 1999). Detta forskningsområde är på stark frammarsch och har stor relevans för olika insatser av folkhälsokaraktär. Också för utvecklingen av nya arbetsmetoder i socialt ar- bete - inte minst prevention - är detta ett angeläget forskningsområde.

\section{Forskning om utsatta kvinnor}

I ett internationellt perspektiv har forskning om utsatta kvinnors livssituationer och behandling legat långt efter i Sverige. På senare år har emellertid intresset ökat för studier av hemlösa kvinnor i storstäderna, missbrukande kvinnor i behandling samt kvinnor som avtjänar fängelsestraff (t.ex. Ungmark 1992; Trulsson 1997; Beijer 1999). Denna forskning har ofta en klar feministisk ansats; den arbetar med begrepp från feministisk teori och framhåller ofta kvinnornas "osynlighet" och utsatthet $i$ vård- och behandling. Från kvinnliga behandlingsforskare framförs hård kritik mot institutionernas oförmåga att möta dessa kvinnors särskilda behov (jfr Trulssons artikel).

\section{Begynnande mansforskning}

Som framgår av artikelurvalet i detta nummer finns ett ökande intresse för forskning som tar sin utgångspunkt i mäns handlingsmönster på olika sociala fält. I denna forskning förs en diskussion om de spänningsförhållanden som råder mellan gamla och nya rollmodeller, mellan den ambitiöse försörjaren och den tillgivne fadern och mellan den machistiske förföraren och den lyssnande och uppmärksamme livskamraten. Denna forskning är ofta feministiskt inspirerad och har en stark betoning på maktförhållanden mellan könen och på den sociala könsordningens konflikter. Men den har också ambitionen att ge utrymme åt männens egna röster, både när det gäller förövarens självförståelse och motiv (kvinnomisshandel, sexuella övergrepp, konsumtionen av porno- 
grafi och köp av sexuella tjänster) och faderns upplevelse av föräldraskapet och dess inverkan på mannens syn på sig själv som man (jfr Johansssons samt Plantin, Månsson \& Kearneys artiklar).

Av denna korta översikt framgår att könsforskningen omfattar vissa teman och avgränsade områden av ämnet socialt arbete. Andra centrala delar av ämnet berörs inte. Det kan således vara intressant att fundera över vilken forskning som saknas och var det finns vita fält som borde utforskas.

\section{Vilken könsforskning borde bedrivas?}

Fyra intressanta områden kan urskiljas:

Ett område gäller arbete och försörjning och olika offentliga organs arbets- och funktionssätt. Det handlar t.ex. om hur kvinnor och män behandlas av försäkringskassan, arbetsförmedlingen eller socialtjänsten och vilka strategier som de olika könen använder för att få del av myndigheternas resurser och få sina behov tillgodosedda. Flera frågor infinner sig: Finns det en könssegregerad praktik hos dessa myndigheter, vilka element består den av och vilka konsekvenser får den för myndigheternas klienter eller brukare? Både Evy Gunnarssons (1993) och Ingegerd Bäckströms (1997) avhandlingar - den ena om kvinnliga socialbidragstagare och den andra om långtidssjukskrivna som genomgår arbetsrehabilitering - tyder på att det förekommer en könssegregerad praktik. Eftersom dessa myndigheter betjänar stora grupper av medborgare, som ofta befinner sig i en utsatt situation under handläggningstiden är detta ett mycket angeläget forskningsområde.
Ett andra område handlar om social service och bemötande hos olika myndigheter $i$ allmänhet. Pedagogisk forskning från Linköpings universitet har t.ex. visat att allmänpraktiserande läkare behandlar sina patienter olika beroende på om de är kvinnor eller män (SOU 1996:133). Samtalen har olika längd och innehåll med olikartat kroppsspråk. Bland läkarna förekommer också könsspecifik kommunikation. Kvinnliga läkare lägger ned mer tid på att samtala med patienterna och förklara sjukdomens orsaker och konsekvenser, osv. Förekommer liknande könsspecifika bemötanden också inom socialt arbete? Man kan tänka sig former av socialt arbete där ett kvinnligt kommunikationsmönster dominerar beroende på könssammansättningen i personalen. Vilka reaktioner eller strategier blir följden hos de besökande klienterna? Och vad blir konsekvenserna för det sociala arbetets utförande? Här handlar det närmast om grundforskning i socialt arbete, en forskning som ännu inte kommit till stånd, kanske beroende på metodmässiga svårigheter.

Ett tredje område gäller patriarkaliska och auktoritära mönster inom institutionsvården och hur de hanteras av personal och intagna. Sådana mönster fortlever litet varstans, men torde vara mera framträdande inom olika slutna vårdsystem t.ex. inom rättspsykiatrin, den sociala ungdomsvården, kriminalvården eller missbruksvården. Mönstren är ofta inbyggda i organisationsformer och arbetssätt, men visar sig också i värderingar och förhållningssätt mellan klienter och personal. En feministisk ansats med utvecklade begrepp från feministisk teoribildning och kvalitativa forskningsmetoder vore säkert fruktbart. Tvärvetenskap- 
liga studier i samarbete med socialantropologer eller etnologer skulle också kunna vara spännande och ge fler perspektiv och begrepp för analys.

Ett fjärde område handlar om arbetsvillkor, organisationsformer och ledarskap inom den sociala sektorns arbetsplatser. Här finns ofta en problematisk organisationsstruktur med många hierarkiska nivåer, brist på styrning och ett otydligt ledarskap (Olsson, 1988; Larsson \& Morén, 1988). Personalen får många och kvalificerade uppgifter och verkar $\mathrm{i}$ en stressande arbetsmiljö med många dagliga konflikter och förtretligheter. Samtidigt ges inte tillräckliga resurser eller information, arbetsledningen är mestadels frånvarande och handledning saknas. I denna mycket betungande arbetssituation utvecklas revirtänkande, destruktivt konfliktbeteende och mobbning. På detta fält skulle man kunna studera könsspecifika problemlösningsmönster, destruktiva och mer konstruktiva arbetssätt samt olika typer av ledarskap, patriarkalt såväl som demokratiskt. Inom den sociala sektorn har man ofta importerat organisationsmönster och ledarskapsstilar från näringslivet, utan att fråga sig om de passar för människovårdande organisationer, som har till uppgift att ge social service och omvårdnad. Könsforskning som studerar nya organisationsformer, ledarskap och arbetssätt inom den sociala sektorn är efterlängtad och borde vara mycket användbar.

Ovanstående områden är bara några exempel på outforskade fält, där könsforskning i ämnet socialt arbete skulle vara fruktbar och angelägen.

\section{Vilka begrepp och ansatser är fruktbara för att utveckla könsperspektiv i socialt arbete?}

Antropologisk forskning visade redan under första hälften av 1900-talet att det som i västerlandet uppfattas som typiskt kvinnliga eller manliga egenskaper är socialt konstruerade genom uppfostran och inlärning. I andra kulturer kan dessa egenskaper vara helt ombytta mellan könen. Det som vi uppfattar som biologiskt grundade skillnader är ofta enbart kulturella konstruktioner. Kön uppkommer således i ett system av sociala relationer. I stället för att definiera "manlighet" eller "kvinnlighet» som ett objekt (en naturlig karaktärstyp, ett beteendemässigt genomsnitt, en variabel, en norm, en roll m.m.) bör vi istället fokusera på de processer och relationer genom vilka män och kvinnor lever sina könspräglade/könsspecifika liv. Den australiske könsforskaren Robert W. Connell (1995) beskriver skapandet av kön som ett sätt att strukturera sociala handlingar. På så sätt, menar han, kan man betrakta kön både som "a product and producer of history». Relationerna mellan könen konstrueras och förändras alltså över tid och formas i interaktion både med de samhälleliga strukturerna och de vardagliga relationerna mellan män och kvinnor.

Idag kan man se flera motstridiga tendenser i kulturen, dels att könsspecifika mönster särskilt bland ungdomar håller på att uppluckras till förmån för en slags androgyn identitet, dels en nostalgisk längtan tillbaka till en mytisk tid då varken män eller kvinnor grubblade över sin identitet (jfr Thomas Johanssons artikel där han diskute- 
rar den oppositionella manligheten kontra den nostalgiska manligheten). Mot denna bakgrund finns det anledning att fundera över det könstänkande som präglar eller genomsyrar det sociala arbetets praktik. Mycket tyder på att många socialarbetare är fast i en kulturell stereotyp av kön som bygger på en enkel uppdelning av "kvinnligt" och "manligt" (jfr Margareta Hydéns artikel). För att komma vidare och överskrida denna enkla och statiska tudelning föreslår vi en mer komplex och pluralistisk förståelse av kön. En sådan finns bl.a. att hämta i de könsteorier som utvecklats både inom mansforskningen (Connell, 1995; Mac an Ghaill, 1996) och den feministiska postmodernismen (Nicholson, 1989; Butler, 1990). Gemensamt för dessa teorier är synsättet att den könsmässiga över- och underordningen på olika nivåer i samhället är förankrad i materiella, sociala och kulturella omständigheter. Patriarkatet upprätthålls således både inom den ekonomiska och offentliga sfären, genom arbetsfördelningen mellan könen, genom arbetsmarknadens struktur och genom socialisationen i familjen. Patriarkaliska drag och förmynderi präglar också socialt arbete i hög grad och bärare av dessa mönster är både män och kvinnor? Varför? Till detta finns många orsaker. En är att maktförhållandena i socialt arbete varit i det närmaste självklara, eftersom man oftast arbetar med marginaliserade och svaga grupper i samhället, som sällan för sin egen talan och har makt att påverka det ojämlika förhållandet mellan socialarbetare och klient.

Trots kampen för jämställdhet är kvinnor fortfarande underordnade män på många områden i samhället. Dessa områden behö- ver naturligtvis kartläggas och utforskas. Men det förekommer också kvinnliga enklaver, där manligt språk och tänkande undertrycks (Kollind, 1994). Såväl manligt som kvinnligt förtryck bör granskas och avslöjas. Uppdelningen mellan manliga och kvinnliga sfärer i samhället är inte lika tydlig som tidigare. Idag förekommer istället både kommunikation och utbyte mellan de båda sfärerna. Kvinnorna har gjort stora inbrytningar på arbetsmarknaden och i den offentliga sfären. Männen har å andra sidan tagit större ansvar för familj och föräldraskap. Det gäller att inte ta vissa traditionella förhållanden för givna utan istället empiriskt undersöka det vardagliga och föränderliga.

I flickors socialisationsprocess har länge betonats vikten av nära relationer, lyhördhet, empati, likhet och beroende av andra. På motsvarande sätt har pojkar uppfostrats till olikhet, självständigt handlande, känslokontroll, tävlande och konkurrens. För könens traditionella roller på arbetsmarknaden och i familjen har detta varit funktionellt. För en ny fadersroll i familjen eller en kvinnlig karriär i offentligheten är dessa könsspecifika drag vare sig funktionella eller konstruktiva sett ur ett förändringsperspektiv. I kvinnogrupper ger de dessutom upphov till rädsla för olikhet, intolerans och destruktiva konflikter.

Med ett alltför snävt perspektiv finns det risk för att man odlar vissa myter, t.ex. att de flesta kvinnogrupper skulle ha en flat och icke-hierarkisk struktur, som gynnar demokratiskt beslutsfattande. Det finns även risk för att vissa problemområden inte blir sedda och utforskade. Ett sådant förbisett område är kvinnors förtryck av kvinnor. Det är väl känt från mobbningssituationer 
på arbetsplatser eller inom behandlingsinstitutioner att kvinnligt förtryck i olika former förekommer. Sådana fenomen måste naturligtvis utforskas, avtäckas i hela dess vidd och om möjligt bekämpas.

Vi vill således varna för en del könsschabloner och istället uppmuntra till nyfikna och kreativa undersökningar av hur det faktiskt förhåller sig. Vi förordar en öppen och odogmatisk inställning beträffande val av frågeställningar och forskningsproblem. Forskning med könsperspektiv handlar ofta om att granska maktförhållanden, avslöja könsförtryckets olika element och påtala könens lika rättigheter och skyldigheter. Det är en kritisk och emancipatorisk forskning om könsfrågorna som behövs. En del uppslag till sådan forskning finns i artiklarna i detta specialnummer av Socialvetenskaplig tidskrift.

\section{Litteratur}

Bak, M (1997): Enemorfamilien, København: Frydenlund

Bäck Wiklund, M \& Bergsten, B (1997): Det moderna föräldraskapet, en studie av familj och kön i förändring, Stockholm: Natur och kultur

Beijer, U (1999): Hemlösa kvinnor i Stockholm, Stockholm: FOU-byrån, Stockholms socialförvaltning

Bäckström, I (1997): Att skilja agnarna från vetet - om arbetsrehabilitering av långvarigt sjukskrivna kvinnor och män, Umeå: Institutionen för socialt arbete, $\mathrm{nr} 22$

Butler, J (1990): Gender Trouble. Feminism and subversion of identity, New York: Routledge

Connell, R W (1995): Masculinities, Cambridge: Polity Press

Gunnarsson, E(1993): I välfärdsstatens utmarker Om socialbidrag och försörjning bland ensamstående kvinnor utan barn, Rapport i socialt arbete nr 64: 1993, Stockholms universitet, Socialhögskolan

Haavind, H \& Andenäs, A (1990): Care and the Responsibility for Children. Creating the Life of Women Creating themselves, uppsats presenterad på konferens i Köpenhamn 1994

Hearn, J (1996): Is masculinity dead? A critique of the concept of masculinity/masculinities ur Mac an Ghaill (red.) Understanding Masculinities, Philadelphia: Open University Press Hedin, UC \& Månsson, SA (1998): Vägen ut-om kvinnors uppbrott ur prostitutionen, Stockholm: Carlssons bokförlag

Hedlund, E (1995): Fruktan för närhet. Om sexualfientligt beteende hos män, Stockholm: Carlssons bokförlag

Henriksson, B (1995): Risk Factor Love. Homosexuality, Sexual Interaction and HIV-prevention, Skriftserien, Socialt arbete, Göteborgs universitet

Holter, Ø \& Aarseth, H (1994): Mäns Livssammanhang, Stockholm: Bonnier

Hydén, LC (1990): De osynliga männen, en social psykologisk studie av manliga prostitutionskunder. FOU-byrån, Stockholms Socialförvaltning, Rapport nr 122

Hydén, M (1994): Woman Battering as Marital Act. The Construction of a Violent Marriage. Oslo: Scandinavian University Press

Hyvönen, U (1993) Ombarns fadersbild, Umeå: Institutionen för socialt arbete, Umeå universitet

Jonsson, G(1969): Det sociala arvet, Stockholm: Tidens förlag

Jonsson, G (1977): Flickor på glid. En studie i kvinnoförtryck, Stockholm: Tiden/Folksam

Kollind, AK (1994): Kärlek, kön \& rådgivning - ett förändringsperspektiv ur Björnberg, Kollind \& Nilsson (red.): Janus och Genus, Stockholm: Brombergs

Kvarnmark, E \& Tidefors Andersson, I (1999): För- 
övarpsykologi. Omvåldtäkt, incest och pedofili, Stockholm: Natur och kultur

Larsson, H \& Morén, S (1988): Organisationens mänskliga insida. Om det sociala arbetets utvecklingsmöjligheter, Umeå: Institutionen för socialt arbete, Umeå universitet

Lennéer-Axelson, B (1989): Männens röster i kris och förändring, Stockholm: Sesam

Leissner, T (red) 1997: Alkohol. Ett psykosocialt, beteende- och samhällssvetenskapligt perspektiv, Lund: Studentlitteratur

Månsson, SA \& Linders, A (1984): Sexualitet utan ansikte. Könsköparna, Stockholm: Carlssons

Nilsson Schönnesson, L (1999): Med livet i fokus. En studie kring livskvalitet hos homosexuella män och heterosexuella kvinnor med hiv, Göteborg: Institutionen för socialt arbete, Skriftserien 1999:3

Olsson, E (1988): Förändring och konflikt. Om mellanmänskliga processer i en vårdorganisation, Lund: Studentlitteratur

Plantin, L \& Månsson, SA (1999): Mäns föräldraskap. Om faderskap och manlighet i ett livsperspektiv, Göteborg: Institutionen för socialt arbete, Skriftserien 1999:6

Mac an Ghaill, M (1996): Understanding Masculinities, Philadelphia: Open University Press
Nicholson, L (1989): Feminism/Postmodernism, New York: Routledge

Sandell, G mfl (1996): Könsköparna. Varför går män till prostituerade?, Stockholm: Natur och Kultur

SOU 1996: 133: Jämställd vård. Olika vård på lika villkor. Huvudbetänkande, utredningen om bemötande av kvinnor och män inom hälso- och sjukvården

SOU 1998: 6: Ty makten är din...Myten om det rationella arbetslivet och det jämställda Sverige. Slutbetänkande från kvinnomaktutredningen.

Takman, J (1966): Socialmedicinsk vardag. Stockholm: Wahlström \& Widstrand

Tikkanen, R \& Månsson, SA (1999): Förhandlad säkerhet och kalkylerade risker- rapport frain en enkätundersökning om socio-sexuella livsstilar och hivriskantaganden bland män som har sex med män, Institutionen för socialt arbete, Göteborg universitet, Skriftserien 1999:7

Trulsson, K (1997): "Det är i alla fall mitt barn!" En studie om att vara missbrukare och mamma skild från barn. Socialhögskolan, Lunds universitet

Ungmark, I (1992): Kvinnor, brott, övervakning, Linköping Studies in Education and Psychology no 34, Linköpings universitet. 